\title{
The Use of Free Software by Brazilian Government between 2018 and 2020
}

\author{
Flávio Gomes da Silva Lisboa \\ UTFPR \\ Curitiba, Brasil \\ https://orcid.org/0000-0002-9396-7944
}

\begin{abstract}
This article presents a quantitative and qualitative exploratory research on the use of free software in the Brazilian government. The data collected refers to the period between 2018 and 2020 . The motivation for the research was the lack of data on the use of free software on the government portal for this topic. Initially, the free software scenario is presented within the government's strategy since 2002 and the criticisms about the effectiveness of policies to promote free software. After explaining the methodology used for data collection, the results are presented. 87 entities were questioned, including ministries, state-owned enterprises, universities, the Federal Chamber, the Federal Senate and the Federal Supreme Court. In addition to the amount of software used, software licenses and software categories were counted, which were defined according to user rankings. State entities were also questioned about the production of free software and the results showed that, in addition to using free software, the Brazilian government also produced free software. Finally, entities were questioned about their acquisition software policies.
\end{abstract}

Keyworkds-Brasil; electronic government; free software; public software; survey.

\section{INTRODUCTION}

In 2002, the Brazilian federal government created an electronic government program. One of his guidelines was the following:

Free software is a strategic resource for the implementation of electronic government: priority must be given to solutions, programs and services based on free software that promote the optimization of resources and investments in information technology, in addition to guaranteeing citizens the right of access to public services without forcing you to use specific platforms; (our translation) [5]

According to the Free Software Foundation [8], free software is software for which "users have the freedom to run, copy, distribute, study, change and improve". Birkinbine [1] says that "free software is viewed as a pragmatic means for meeting the goals of digital inclusion". Considering digital inclusion as part of social inclusion, free software becomes an instrument of interest for state policies.

As one of the actions of the electronic government program related to free software, in 2010 Brazil launched the Public Software Portal of Brazil. "Brazilian public software is a specific type of free software that meets the
Marilene Zazula Beatriz UTFPR

Curitiba, Brasil

https://orcid.org/0000-0002-8307-7438

modernization needs of public administration" (our translation) [7]. In March 2020, this portal had a total of 69 free software.

In addition to the Public Software Portal, the Brazilian government published content on actions related to free software on the portal http://softwarelivre.gov.br until 2015. In this portal a survey of data on the use of free software in the federal government, conducted in 2010 [3]. This survey measured the use of free software in 129 state entities, including ministries, agencies, companies, universities and institutes. The free software was grouped into five categories: email, Internet servers, information systems, operating systems and Office Suite. Usage was measured at five levels: (i) data not provided / not applicable; (ii) there is no significant use of free software; (iii) little use or beginning of the free software migration process; (iv) average use or in the free software migration process; and (v) significant use of free software. One of the conclusions of this survey was that there was a relative difficulty in initiating the processes of use of free software indicated by the guidelines of the electronic government program in Brazil. This is the only survey available on this portal.

Birkinbine [1] argues that although "free software projects and policies have continued to advance within state institutions, [...] the effectiveness of these projects and policies remains relatively unexplored". In this scenario, this article intends to investigate the use of free software in the Brazilian federal government, in order to build a reference for a more in-depth study on the effectiveness of this use.

\section{METHODOLOGY}

It was not possible to reproduce the methodology used by Machado, Hernández, Kuhn, Camara and Pastore [3], because it was carried out with the support of a governmental committee for the implementation of free software (CISL), which became extinct in 2016, according to reported by Lima and Sobral [2]. Therefore, another methodology was adopted.

The methodology adopted consisted of a quantitative and qualitative exploratory research. Quantitative because it measured the amount of free software used by each entity. Qualitative because it defined more specific software categories than those used by the CISL survey.

We used four data collection instruments. One of them was the electronic system of the Brazilian Citizen 
Information Service (e-SIC). Through this system, any Brazilian citizen can request information from a federal public administration body, which includes executive branch entities.

The others were the electronic forms to request information from the institutional websites of the Federal Chamber and the Federal Senate, which comprise the legislative branch, and from the institutional website of the Federal Supreme Court, which is the highest instance of the judiciary.

Brazil has an access to information law, Federal Law 12527 of 2011, which guarantees Brazilian citizens access to information and documents under the responsibility of executive, legislative and judicial bodies. The bodies have 20 days to respond to requests and can extend the response for 10 days. Eventually, it is necessary to appeal to a higher body, when the information is incomplete or does not correspond to what is requested.

Three questions were presented:

- What are the free software used by the institution and what are they used for?

- Does the institution purchase proprietary software even though equivalent free software is available?

- Has the institution developed or is developing any free software?

The first question had the objective of knowing the amount of software used and what software was used. The second question was aimed at identifying the entity's internal policy on the use of free software. The third question was aimed at finding out if the entity, in addition to being a user, would be a producer of free software.

The limited time to complete the article, considering the collection and analysis of data, prevented the consultation of the 129 entities questioned by the CISL. It was decided to reduce the number of entities interviewed for 14 ministries, 7 state-owned enterprises (SOEs) and 63 universities, which, together with the Federal Chamber, the Federal Senate and the Federal Supreme Court, totaled 87 entities to be consulted. Requests for information were sent and answered between 2018 and 2020. Sometimes it was necessary to appeal or open a new request to obtain the information. In some cases, the information was not provided.

\section{RESULTS}

\section{A. Amount of free software}

Figure 1 shows the amount of free software used by the questioned ministries. The largest user of free software among the ministries is the Ministry of the Economy, with 85 softwares. The ministries that use free software the least are the Ministries of Environment and Foreign Affairs, with 8 each. 3 ministries, Economy, Education and Environment, declared that they produced free software.

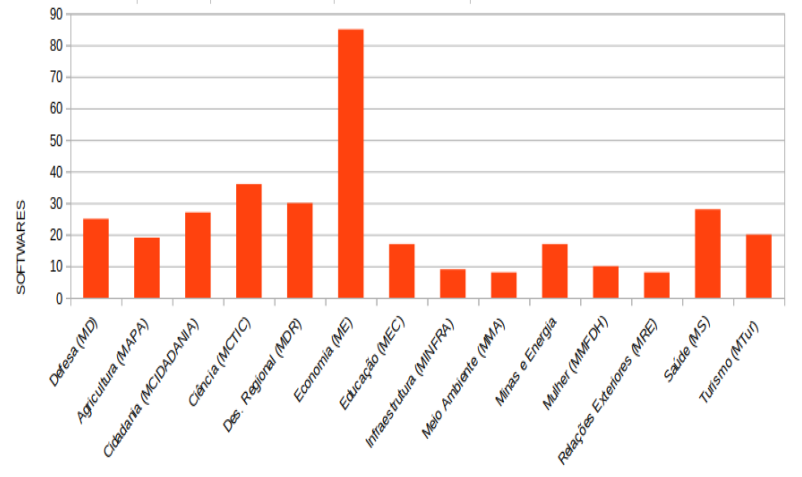

Fig. 1. Amount of free software per ministry.

Of the 7 SOEs questioned, 4 belong to the 5 main groups of Brazilian SOEs: ELETROBRAS, PETROBRAS, Banco do Brasil (BB) and Caixa Econômica Federal (CEF). The other 3 companies are the 2 state information technology companies, SERPRO and DATAPREV, and the postal and telegraph company. PETROBRAS did not report the free software used, claiming that it does not classify its software. $\mathrm{BB}$ and $\mathrm{CEF}$ answered only that they use free software without saying what they are. But in the answer on the production of free software, BB reported on the software that it produced and uses. The Brazilian state company that uses free software the most is SERPRO, with 130 software identified. DATAPREV, which is in the same line of business as SERPRO, uses 38 free software. BB, SERPRO and DATAPREV stated that they produced free software. Figure 2 shows the proportion of use of free software in state companies.

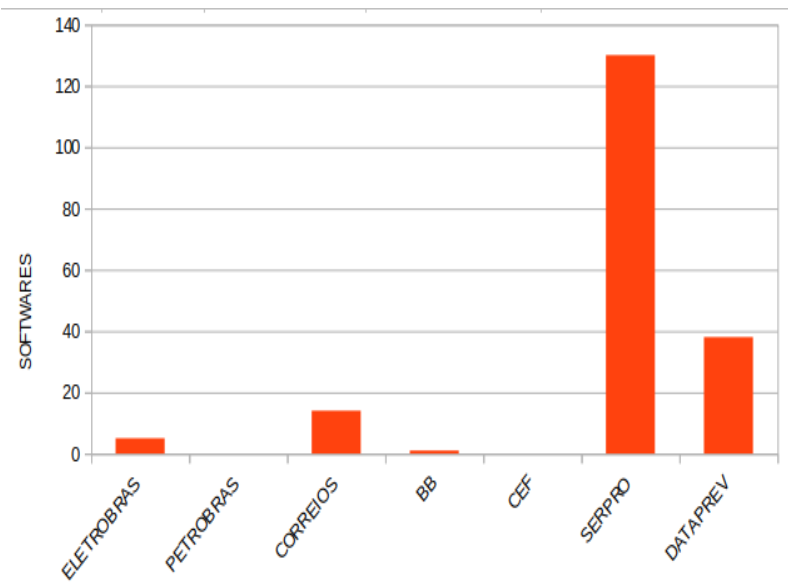

Fig. 2. Amount of free software by state company.

Of the 63 federal universities questioned, only one, UFPA, did not answer what free software it uses, claiming that it has no control over the acquisition of software. The top 5 users of free software among universities are UNIFAL, UFMG, UFSM, UFCSPA and UFG. The amount of software used by each one is shown in Table 1. 
TABLE I

THE 5 LARGEST USERS OF FREE SOFTWARE AMONG FEDERAL UNIVERSITIES.

\begin{tabular}{|l|l||r|}
\hline University & Brazil Region & $\begin{array}{l}\text { Amount of } \\
\text { softwares }\end{array}$ \\
\hline UNIFAL & Southest & 75 \\
\hline UFMG & Southest & 72 \\
\hline UFSM & South & 66 \\
\hline UFCSPA & South & 61 \\
\hline UFG & Center West & 60 \\
\hline
\end{tabular}

The 5 universities that use the least free software are UFPel, UFCG, UFS, UNIR and UFPA. The amount of software used by each one is shown in Table 2.

TABLE II

THE 5 FEDERAL UNIVERSITIES THAT USE FEW FREE SOFTWARE

\begin{tabular}{|l||l||r|}
\hline University & Brazil Region & $\begin{array}{l}\text { Amount of } \\
\text { softwares }\end{array}$ \\
\hline UFPel & South & 3 \\
\hline UFCG & Northeast & 2 \\
\hline UFS & Northeast & 2 \\
\hline UNIR & North & 1 \\
\hline UFPA & North & 0 \\
\hline
\end{tabular}

8 universities responded that they produced free software: UFRA, UFCG, UFESBA, UFF, UFOP, UNIFAL, UFG and UFRGS. 3 are from the north region, 3 from the southeast region, 1 from the central west region and 1 from the south region.

TABLE III

THE 5 LARGEST USERS OF FREE SOFTWARE AMONG FEDERAL UNIVERSITIES BY REGION.

\begin{tabular}{|l||l||r|}
\hline University & Brazil Region & $\begin{array}{l}\text { Amount of } \\
\text { softwares }\end{array}$ \\
\hline UNOFA & Northern & 44 \\
\hline UFOB & Northeast & 38 \\
\hline UNIFAL & Southeast & 75 \\
\hline UFSM & Southern & 66 \\
\hline UFG & Center West & 60 \\
\hline
\end{tabular}

The university that uses less free software in the northern region is UFPA, without software. In the northeast region they are UFCG and UFS with 2 each. In the southeast region it is UFRRJ with 3. In the southern region it is UFPel with 3. In the central west region it is UFGD with 3.

The Federal Chamber requested an extension of time to comply with the data request, but did not respond within the given period and until the conclusion of this article. The Federal Senate responded that it would not report for security reasons. the Federal Supreme Court responded that it uses only 4 free softwares.
476 different free softwares were identified in all responses. The five most used free software are: LibreOffice, PostgreSQL, Apache HTTP Server, MySQL and Zabbix. Table 4 shows how many entities use each of the software.

\section{TABLE IV}

THE 5 MOST USED FREE SOFTWARE FOR THE BRAZILIAN GOVERNMENT

\begin{tabular}{|l||l||r|}
\hline Software & Category & Users \\
\hline LibreOffice & Office Suite & 51 \\
\hline PostgreSQL & Database & 43 \\
\hline Apache HTTP & Web & 38 \\
Server & Application & \\
& Server & 38 \\
\hline MySQL & Database & 31 \\
\hline Zabbix & Monitoring & \\
\hline
\end{tabular}

There are 243 free software with only one government entity as user. 186 categories of software were identified. The 5 most frequent categories are: Framework, Monitoring, Integrated Development Environment, Operational Systems and Data Bank. Table 5 shows how many free software were identified in each of these categories.

TABLE V

THE 5 MOST FREQUENT CATEGORIES OF FREE SOFTWARE IN THE BRAZILIAN GOVERNMENT

\begin{tabular}{|l|r|}
\hline Category & Ocurrences \\
\hline Framework & 25 \\
\hline Monitoring & 17 \\
\hline Integrated Development & 15 \\
Environment & \\
\hline Operating Systems & 13 \\
\hline Database & 11 \\
\hline
\end{tabular}

In the Framework category, the most used free software is Spring with 5 occurrences. In the Monitoring category the most used is Zabbix with 31 occurrences. In the Integrated Development Environment category it is Eclipse with 27. In the Operating Systems category it is Ubuntu, with 30 occurrences. And in the Database category is MySQL with 38 occurrences.

106 categories have only one free software occurrence. The most used internet browser is Mozilla Firefox with 28 occurrences. The 5 most used programming languages are Java, with 23 occurrences, PHP with 19 occurrences, Python with 7 occurrences, $\mathrm{R}$ with 6 occurrences, and Ruby with 2 occurrences.

The 5 free software licenses with the highest incidence are: GPLv2, Apache 2, GPL, GPLv3 and MIT. Table 6 shows the number of occurrences per license. 
TABLE VI

THE 5 MOST FREQUENT FREE SOFTWARE LICENSES IN THE BRAZILIAN GOVERNMENT

\begin{tabular}{|l|r|}
\hline License & Ocurrences \\
\hline GPLv2 & 103 \\
\hline Apache 2 & 88 \\
\hline$G P L$ & 61 \\
\hline GPLv3 & 47 \\
\hline MIT & 33 \\
\hline
\end{tabular}

\section{B. Software acquisition policy}

The question "Does the institution buy proprietary software even though equivalent free software is available?" be understood as:

If there are two softwares with exactly the same functionalities, but one is free software and the other is not, which software will be chosen?

The responses were grouped into six categories, which are shown in Table 7. Most of the entities responded that the acquisition of proprietary software depends on technical evaluation.

TABLE VII

ACQUISITION OF PROPRIETARY SOFTWARE WHEN THERE IS EQUIVALENT FREE SOFTWARE

\begin{tabular}{|l||r|}
\hline Answer & Ocurrences \\
\hline $\begin{array}{l}\text { Yes, it buys and do not justify the } \\
\text { reason. }\end{array}$ & 12 \\
\hline $\begin{array}{l}\text { No, it does not buy and does not } \\
\text { justify the reason. }\end{array}$ & 9 \\
\hline $\begin{array}{l}\text { Yes, it buys and justifies the } \\
\text { reason. }\end{array}$ & 14 \\
\hline $\begin{array}{l}\text { No, it does not buy and justifies } \\
\text { the reason. }\end{array}$ & 6 \\
\hline Did not answer & 41 \\
\hline Depends on technical evaluation & 5 \\
\hline
\end{tabular}

From all entities questioned, 7 mentioned a 2019 regulatory instruction from the Ministry of Economy as a guide document for software purchases.

\section{Free software production}

14 entities declared that they produced free software: 3 ministries, 3 state companies and 8 universities. The Economy Ministry said it had developed Agatha, a risk management system that is available on the Public Software Portal of Brazil. The Ministry of Education claimed to have developed the software DERC, but a source code repository for that software has not been found. The Education Ministry said it had developed the software i3Geo, available on the Public Software Portal.
BB claimed to have developed the PW3270 software, available on the Public Software Portal.

SERPRO claimed to have produced 840 open source softwares, but after checking the source code repositories and licenses, it was found that it produced only 4 free softwares: AlienDroid, Demoiselle Framework, ExpressoV3 and Sagui. Two of them are available on the Public Software Portal. DATAPREV claimed to have developed 3 free software, all available on the Public Software Portal: CACIC, COCAR and SGA. DATAPREV also reported that it had an open source project repository on Github ${ }^{1}$.

UFRA and UFOP said they had developed free softwares, but did not say which ones. UFCG said it produced the Integrated Systems Portal (PSI) as free software, but no source codes were found. UFESBA stated that all selection systems for university admission are open source, but did not indicate where the codes are. UFF said it produced Uffmobileplus as free software, but no source codes were found. UNIFAL responded that it had not developed free software, but a story was found on the university's own website that contradicts this response, with the information that it produced the ForPDI / ForRisco software. UFG reported developing Weby, available on Github (https://github.com/cercomp/weby). UFRGS replied that it had an open source project repository on Github: https://github.com/ufrgs

The Federal Senate reported that it did not produce free software, but there is news that PRODASEN, the Senate information technology company, produced the free software LeXML (https://github.com/lexml).

\section{CONCLUSION}

The entities interviewed reported 142 non-free softwares as if they were free softwares. These softwares include freeware, shareware, and proprietary licenses. The two nonfree softwares most mentioned as if they were free softwares were Google Chrome, by 14 entities and Foxit Reader by 9 entities. This result made it possible to realize that several entities confuse free software related to freedom with free software related to price. In some cases, even non-free software was reported as being free (as in freedom).

Some entities mentioned communication protocols, specifications or methodologies as if they were software. Some examples are: CAS (Central Authentication Service), DHCP (Dynamic Host Control Protocol), DNS (Domain Name System), HTML (HyperText Markup Language), NFS (Network File System), PWA (Progressive Web Application) and SMTP (Simple Mail Transfer Protocol).

From the sample questioned, it can be said that the largest user of free software in the Brazilian government is SERPRO, one of the state information technology companies, with 130 software. In addition, there is a master's study on free software production at SERPRO [4].

It was possible to verify that the use of free software in the organs of the executive branch is greater than in the organs of the legislative and judicial branches, at least at the federal level.

1https://github.com/dataprev 


\section{ACKNOWLEDGMENTS}

We thank all professors of Program of Postgraduate in Technology and Society of UTFPR - PPGTE.

\section{REFERENCES}

[1] Birkinbine, B.: Free Software as Public Service in Brazil: An Assessment of Activism, Policy, and Technology. International journal of communication. $\mathrm{v} \quad .10 \quad$ (2016) 3893-3908 http://ijoc.org/index.php/ijoc/article/view/4974. Accessed on 9 jul. 2017.

[2] Lima, Alberto Jorge Silva de. Sobral, André Vinícius Leal. Tecnologias da Informação e Comunicação e Promessas de Autonomia no Brasil: das Histórias da Política Nacional de Informática à Política de Fomento ao Software Livre. Anales. V Simposio de Historia de la Informática e América Latina y el Caribe. Rio de Janeiro. (2018) 373-386.

[3] Machado, C. R. Hernandez, J; Kuhn, D. L. Camara, F. Pastore, P. F. Uso de Software Livre no Governo Federal: Investigando Estágio Atual e definindo (novos) Parâmetros de Acompanhamento. Anales. $X X X$ Congresso da $S B C$. II
Workshop de Computação Aplicada em Governo Eletrônico. Belo Horizonte. (2010)

www.inf.pucminas.br/sbc2010/anais/pdf/wcge/st05_02.pdf $>$. Accessed on 9 feb. 2018.

[4] Lisboa, F. G. S.: Produção de software livre por uma empresa estatal de tecnologia da informação: um estudo de caso sob a perspectiva da tecnologia social. Master Dissertation. Universidade Tecnológica Federal do Paraná. Curitiba. (2019)

[5] BRASIL: Governo Digital: Do Eletrônico ao Digital. (2019) https://www.gov.br/governodigital/pt-br/estrategia-de-governancadigital/do-eletronico-ao-digital. Accessed on 28 mar. 2020.

[6] BRASIL: Painel do Panorama das Estatais. (2020) http://www.panoramadasestatais.planejamento.gov.br. Accessed on 29 mar. 2020.

[7] BRASIL: Software Público. https://www.gov.br/governodigital/pt-br/software-publico. Accessed on 28 mar. 2020.

[8] FREE SOFTWARE FOUNDATION: What is free software (2001) https://www.gnu.org/philosophy/free-sw.en.html. Accessed on 28 mar. 2020. 